\title{
Application of wavelet transform for evaluation of hydrocarbon reservoirs: example from Iranian oil fields in the north of the Persian Gulf
}

\author{
M. R. Saadatinejad ${ }^{1,2}$ and H. Hassani ${ }^{1}$ \\ ${ }^{1}$ Amirkabir University of Technology, Mining, Metallurgical and Petroleum Engineering, Tehran, I. R. Iran \\ ${ }^{2}$ NIOC, Tehran, I. R. Iran \\ Correspondence to: H. Hassani (hhassani@aut.ac.ir)
}

Received: 21 May 2012 - Revised: 10 February 2013 - Accepted: 18 February 2013 - Published: 8 April 2013

\begin{abstract}
The Persian Gulf and its surrounding area are some of the biggest basins and have a very important role in producing huge amounts of hydrocarbon, and this potential was evaluated in order to explore the target for geoscientists and petroleum engineers. Wavelet transform is a useful and applicable technique to reveal frequency contents of various signals in different branches of science and especially in petroleum studies. We applied two major capacities of continuous mode of wavelet transform in seismic investigations. These investigations were operated to detect reservoir geological structures and some anomalies related to hydrocarbon to develop and explore new petroleum reservoirs in at least 4 oilfields in the southwest of Iran. It had been observed that continuous wavelet transform results show some discontinuities in the location of faults and are able to display them more clearly than other seismic methods. Moreover, continuous wavelet transform, utilizing Morlet wavelet, displays low-frequency shadows on 4 different iso-frequency vertical sections to identify reservoirs containing gas. By comparing these different figures, the presence of low-frequency shadows under the reservoir could be seen and we can relate these variations from anomalies at different frequencies as an indicator of the presence of hydrocarbons in the target reservoir.
\end{abstract}

\section{Introduction}

Many geophysical studies have been done to analyze the structure of subsurface reservoirs; these have lead to exploring many new petroleum reservoirs, as they help us to simulate images from reservoir stratigraphy and understand the paleo-depositional environments. Spectral analysis, which is a quick and important method in seismic interpretation, provides a strong tool to study these types of subsurface layers.

Seismic data, being non-stationary in nature, have varying frequency content in time. The time-frequency decomposition (also called spectral decomposition) of a seismic signal aims to characterize the time-dependent frequency response of subsurface rocks and reservoirs. Castagna et al. (2003) used spectral analysis to detect low-frequency shadows beneath hydrocarbon reservoirs. Since time-frequency mapping is a non-unique process, various methods exist for time-frequency analysis of non-stationary signals such as fast Fourier transform (FFT), continuous wavelet transform (CWT), S-transform, and matching pursuit decomposition (MPD). This paper aims at investigating the wide usages of CWT in seismic studies (Sinha et al., 2005).

Over the past two decades, wavelet transform has been applied in many branches of science and engineering. The continuous wavelet transform (CWT) provides a different approach to time-frequency analysis. The continuous wavelet transform utilizing a complex Morlet analyzing wavelet has a close connection to the Fourier transform and is a powerful analysis tool for decomposing broadband wave field data. A wide range of seismic wavelet applications have been reported over the last three decades (Liner, 2010).

The objectives of this investigation are to use abilities of CWT methods for describing how CWT much better identifies (1) geological structures such as faults and (2) the presence of hydrocarbon in reservoirs than the other seismic methods. These reservoirs are located in different locations in onshore and offshore oilfields of the Persian Gulf in the 
SW of Iran. All target formations had more complexities in structure than stratigraphy.

\section{Geology}

\subsection{Geology of the Abadan Plain}

\subsubsection{Stratigraphy and structural geology}

The Abadan plain and Dezful embayment contain two types of structural closures: very gentle $\mathrm{N}-\mathrm{S}$ to NE-SW-trending basement-cored anticlines in the SE, and open to tight, NWSE-trending thrust-related folds in the NE (Zagros fold and thrust-related anticline in the NE) (Zagros fold and thrust belt) (Abdollahie Fard et al., 2006).

A useful field of structural analysis called inversion tectonics was used. Such a tectonic scenario requires a homogeneous basement plate undergoing deformation that does not contain any significant inherited fault zones that might be reactivated within the applied stress field.

Figure 1 shows two seismic profiles which cross the Abadan field orthogonally. The profile in Fig. 1a is flattened at the top of the Sarvak formation and the profile in Fig. $1 \mathrm{~b}$ is flattened at the top of the Kazhdomi formation. This flattening helps to establish possible kinematics. These figures indicate that there was no significant tectonic activity during deposition of the formations underlying the Sarvak formation. Deformation of the Gotnia and younger stratigraphic section occurred prior to deformation of the Sarvak, and older rocks above the Gotnia detachment and the Gurpi and Pabdeh formations show thinning in the crest of the anticline (possibly in late Cretaceous to Tertiary) (Saadatinejad and Sarkarinejad, 2011).

\subsection{Geology of the Persian Gulf (northwestern)}

The Persian Gulf constitutes what is referred to in the plate tectonic literature as the 'Arabian Plate' and/or the "Middle East sedimentary basin" which is approximately $3000 \mathrm{~km}$ in length and $2000 \mathrm{~km}$ in width. It is bound from the north by the southeastern Turkey Bitlis suture, to the west by the Red Sea, to the east by the Zagros Mountains (Zagros thrust), and to the south by the Gulf of Oman and Owen Fracture Zone in the Arabian Sea.

The major structural features of the area, with their roots in the Precambrian basement, are the results of two major tectonic stages. The first tectonic phase is the Amar collision, which occurred 620-640 million years ago along the northsouth-trending Amar weak zone in the Saudi Arabian Shield. The second tectonic stage corresponds to the Najd rift system with about $300 \mathrm{~km}$ width and a general northwest-southeast trend (parallel with the present Zagros Mountains trend) that took place about 530-570 million years ago. These two major tectonic events, especially the former one, are responsible for the formation of the Qatar/Fars High, which divides

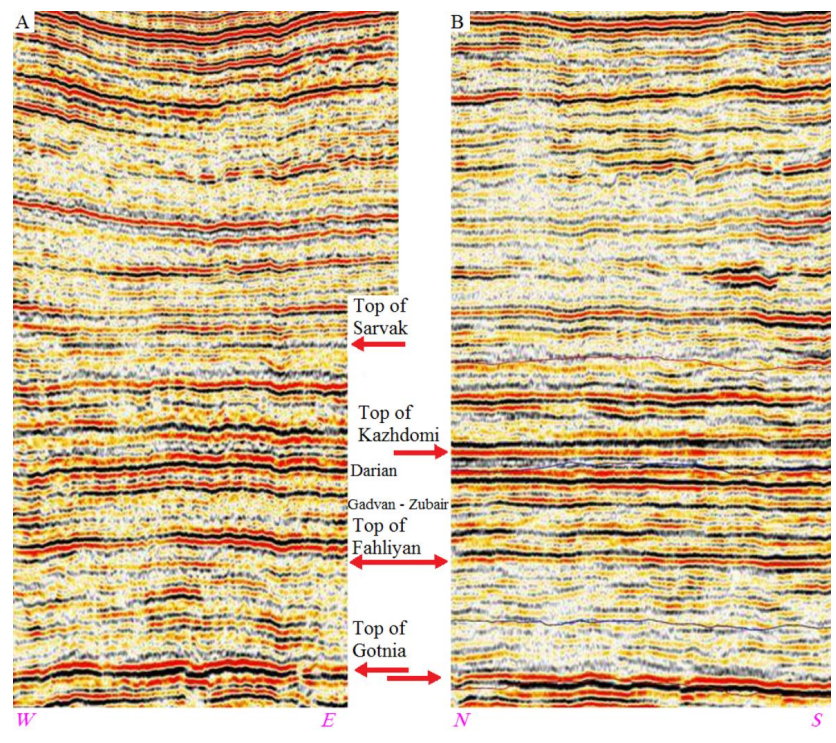

Fig. 1. (a) Seismic line showing flattening at the top of the Sarvak formation. (b) Seismic crossline showing flattening at the top of the Kazhdomi formation (Saadatinejad and Sarkarinejad, 2011).

the Persian Gulf sedimentary basin into the northern and southern basins with somewhat different sedimentary environments and even hydrocarbon habitats. This region holds over two thirds of the oil and one third of the gas reserves discovered in the world. This is due to a combination of some favorable factors in this region. The most important factor is the prolonged and almost uninterrupted sedimentation history since Precambrian time. Sedimentation of prone source rocks and numerous good quality reservoir and cap rocks, combined with the presence of super-giant structures, salt halo kinesis and the Zagros orogeny are among the other major favorable factors.

The Persian Gulf Arabian Plate basin is an asymmetric basin in which the crystalline basement floor has a gentle dip to the northeast (about 20 degrees). The deepest part of the basement floor is some $14-15 \mathrm{~km}$ below sea level, which is now located under the foot of the Zagros Mountains. The plate boundaries exhibit all types of tectonic regimes, from the sea floors spreading from the Red Sea in the west to the Zagros collision zone to the northeast.

\subsubsection{Stratigraphy and structural geology}

The Persian Gulf basin is located within the regional tectonic frame of the Arabian and Iranian plates. The Persian Gulf forms the northeast portion of the anticlockwisemoving Arabian Plate. It is perhaps the archetype Holocene arid carbonate ramp, extending northeast across the gently sloping Arabian Shield as water depth increases from largely emergent sebkhas to depths in excess of $80 \mathrm{~m}$ along the Zagros Mountains' foredeep of Iran (Ghazban, 2007). 
The Persian Gulf occupies a classic foreland basin, filled in part by the terrigenous sediments delivered axially by rivers from the northwest, and in part from allochthonous carbonate sediments generated across the ramp surface. During the evolution of the Persian Gulf, development of salt deposits in the Persian Gulf basin is considered as one of the major geological events; in fact, it was formed during periods of intense evaporation. Salt deposits with a thickness of about $4000 \mathrm{~m}$ are known to occur in the surrounding region and underneath the Persian Gulf. The formation of the Persian Gulf can be seen in context of three events:

1. Movement of the Arabian Plate into its present position.

2. Influence of tectonic movements on the longitudinal morphological features on either side of the Persian Gulf.

3. Formation of submarine platforms during the Holocene transgression.

Nowadays, the Persian Gulf is a shallow depression that tectonically evolved during the late Tertiary. The steep slope on the Iranian side is related to the folding of the Zagros orogeny, whereas the low dipping on the Arabian side is due to gentler tectonic movements (Ghazban, 2007).

The most important oil fields in Iran are adjacent to the other countries on shore of the Persian Gulf from the west to east. The lithology of the main reservoirs in the Persian Gulf and it surroundings is limestone, and the main oil reservoirs are members of the Sarvak formation (Cenomanian), especially Mishrif. The lithological column of southwest Iran that has been used for the oil field of the Persian Gulf is displayed in Fig. 2.

\section{Theory and methodology}

\subsection{Spectral analysis}

\subsubsection{Basic concepts of spectral decomposition}

Spectral decomposition provides a better method for quantifying and visualizing subtle seismic features and allows the geoscientist to analyze and map features using tuning effects and delineating phase. This improvement in seismic processing and interpretation procedures is achieved by assuming that time series are non-stationary and then decompose the seismic signal into discrete frequency components in a nonstationary sense This allows the geoscientist to analyze and map seismic features as a function of spatial position, travel time, frequency, amplitude and phase. This method pertains to a novel approach in geophysical data processing and interpretation of seismic data, which allows the interpreter to visualize, interpret, and quantify the seismic response to an extent that was previously unattainable.
The basis of the spectral decomposition procedure is the thin-bed tuning effect, which occurs when traces from top and down layers have a constructive interface. In this effect, the peak amplitude response will occur at $1 / 4$ wavelength of the dominant period. So, in this state, traces have the highest amplitude value and become highlighted, while thickness layers less than this are not detectable in the seismic sections. In addition, there is an inverse relation between wavelength and frequency for thin bed detection and spectral decomposition used from this relation, i.e., with frequency increasing, wavelength (or minimum thickness detectable) decrease and vice versa.

In fact, spectral analysis converts seismic data from the time domain to the frequency domain. One basic concept could be both examining data in the time domain at different frequencies and comparing the response to provide significant insight into the details.

\subsection{Synthetic and laboratory models}

Gas-bearing zones have an important role in attenuating seismic signals, and this effect appears below the gas-including zone. This effect is called low-frequency shadows under hydrocarbon reservoirs, and tends to attenuate the amplitudes of high frequencies. Goloshubin et al. (2002) conducted a set of laboratory ultra-sonic experiments to investigate the differences in reflections from dry, water and oil-saturated layers. The investigation was done in such a way that the wave propagation in the laboratory model approximated wave propagation in standard practice. The physical modeling data were recorded using a common offset gathering observation system shown in Fig. 3a for both water and oil saturation, and the offset was practically equal to zero. A significant difference is seen between the seismic response of the porous layer dry zone, water-saturated zone, and oil-saturated zone. The very low frequency "bright spot" with phase shift is associated with oil saturation. For realistic data, 2-D seismic data were used to investigate the low-frequency effects from oilsaturated reservoir zones. The frequency-dependent processing was done to get low-frequency images of the reservoirs. In Fig. 3b, wavelet transforms were used for frequency dependent velocity analysis and imaging in oil fields of Western Siberia. As can be seen in this Figure, the oil-saturated domains of both parts of the reservoir create low-frequency $(<15 \mathrm{~Hz})$, high-amplitude effects (red) for reflected seismic energy.

In another study, Burnett and Castagna (2004) studied this subject by constructing a laboratory model to illustrate the examination of the detailed reflectivity and published their results as a plot of frequency changing vs. amplitude for oil, gas and water reservoir bearing. According to their study, anomalies usually highlighted distinguishably between 8 to $20 \mathrm{~Hz}$ and 28 to $35 \mathrm{~Hz}$ for gas and oil reservoirs, respectively, and differ for limestone and sandstone reservoirs. Figure $3 \mathrm{c}$ shows a classical bright spot gas reservoir from the Gulf of 


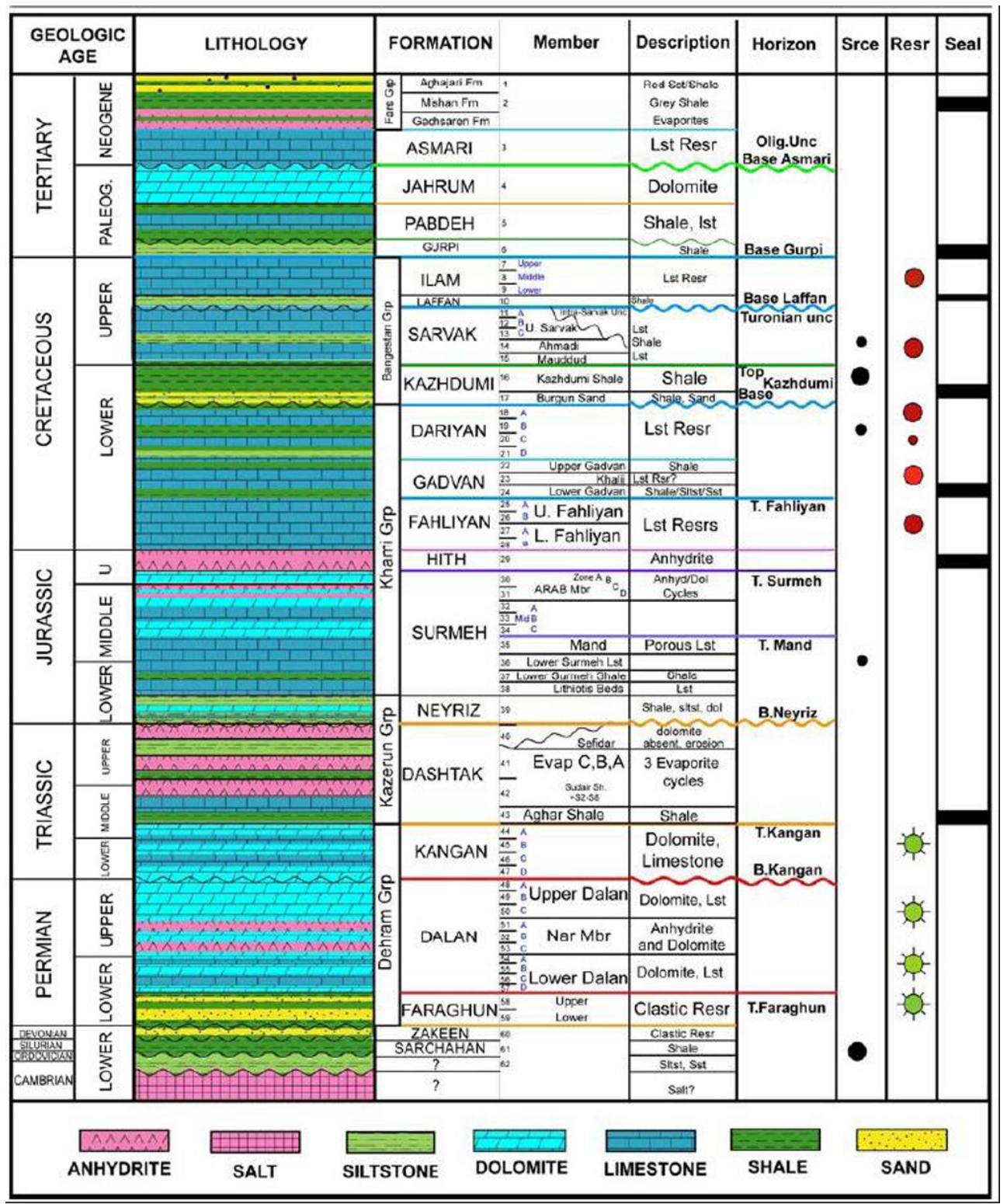

Fig. 2. General stratigraphic column in the Persian Gulf (Ghazban, 2007).

Mexico shelf. Spectral decomposition produces a time frequency gathering that shows the progressive drop in peak frequency with record time caused by attenuation, and also shows the abnormally low frequency of the reservoir reflection (Castagna and Sun, 2006).

\subsection{The CWT method}

CWT is used as an applying method in many sciences and provides a different approach to time frequency analysis (Sinha et al., 2005; Dimri et al., 2005). The CWT is an alternative method for analyzing a signal. In the CWT, wavelets dilate in such a way that time support changes for different frequencies. Smaller time support increases the frequency support, which shifts toward higher frequencies. Similarly, larger time support decreases the frequency support, which shifts toward lower frequencies. Thus, when the time resolution increases, the frequency resolution decreases, and vice versa (Mallat, 1999). It provides representations of the frequency band from the scaled wavelet and has an advantage as it does not relate to a fixed window (Castagna and Sun, 2006) that caused high resolution for CWT as this method represents a good and clear image from reservoir structural characteristics and detects low-frequency shadows (Castagna et al., 2003) under petroleum (affected by gas) reservoirs. Due to this ability, we used the CWT method to identify the hidden and undefined structural (fault and fracture) systems in reservoirs and below formations (Saadatinejad and Sarkarinejad, 


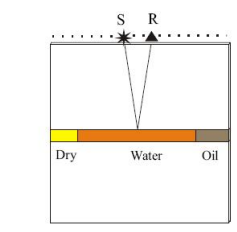

Data acquisition design

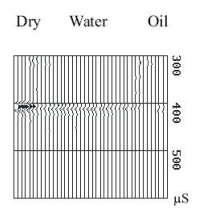

High frequency $(\mathrm{h} / \lambda>1)$

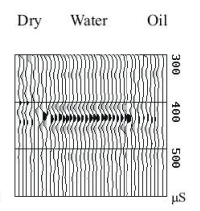

Low frequency $(1>\mathrm{h} / \lambda>0.2)$

and

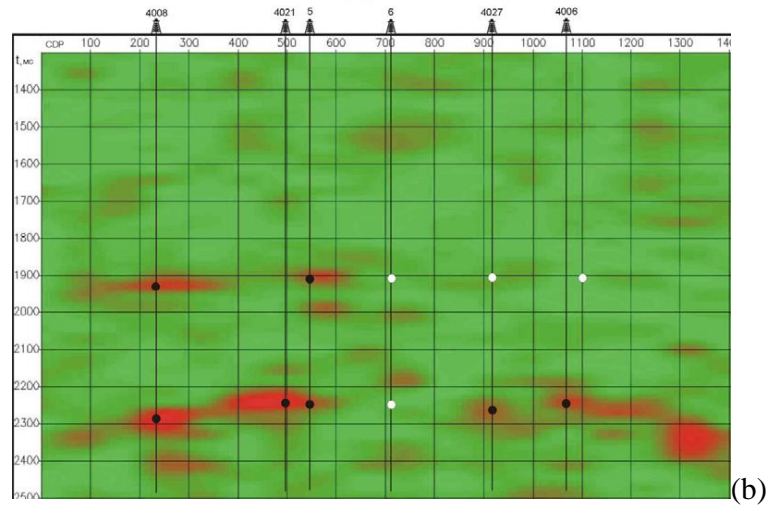

Frequency

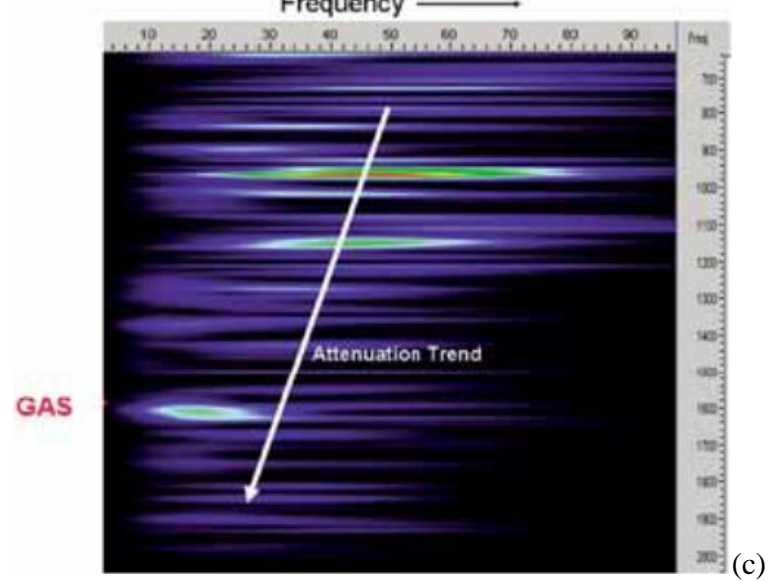

Fig. 3. (a) Laboratory seismic reflection experiment (left panel), and data filtering results, (b) low-frequency results that show the presence of oil in wells (black circles) in the West Siberian oil field (Goloshubin et al., 2002), and (c) time-frequency analysis using spectral decomposition for a seismic trace containing a gas reservoir. The white line illustrates the progress reduction of the peak frequency due to attenuation. The gas reservoir has anomalously low peak frequency (Castagna and Sun, 2006).

2011). The study was conducted on the use of a spectral decomposition method for the purpose of direct hydrocarbon detection through frequency anomalies in a geologically and seismically challenging area.

\subsubsection{Choosing the suitable wavelet}

The wavelet accounts for the most important part in the wavelet transform procedure and a good selection affects the results of the transform. In geoscience studies, especially in seismic investigations, three wavelets play important roles.

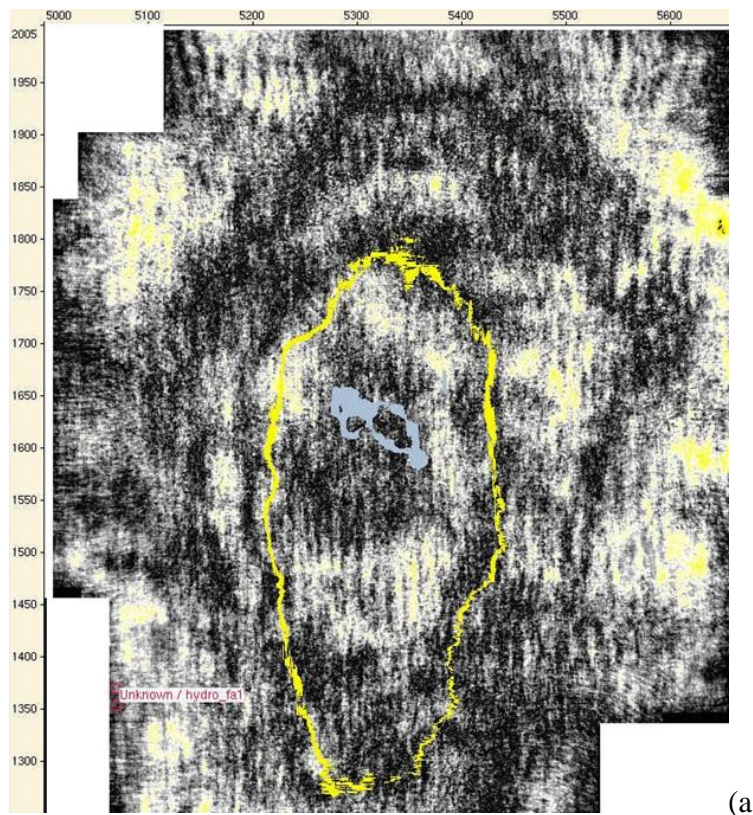

(a)

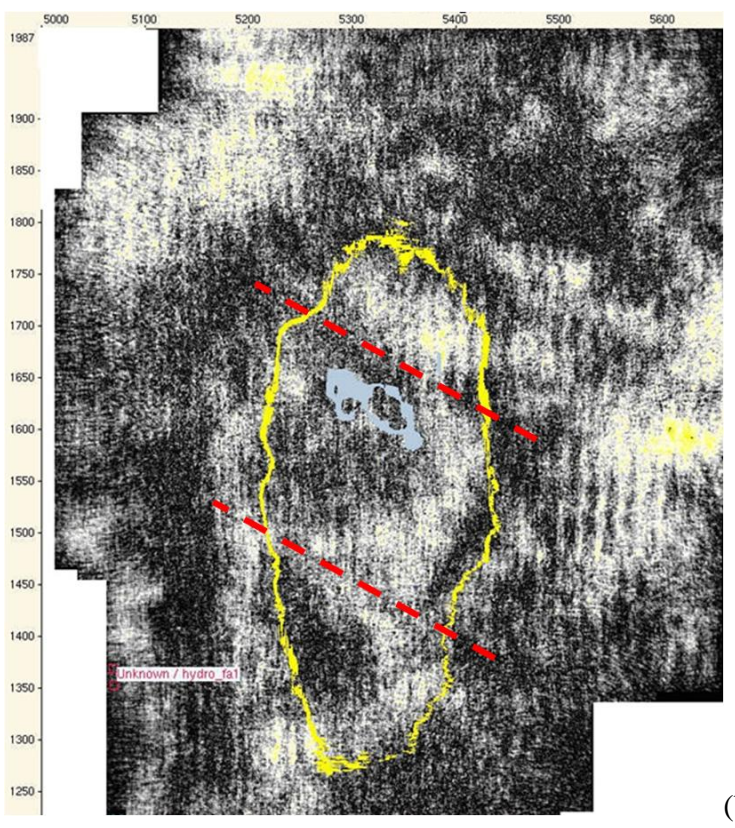

(b)

Fig. 4. Comparison between two main methods of spectral decomposition. (a) FFT and (b) CWT results. Red dashed lines in(b) display the abilities and advantages of the CWT technique in fault detection and illustration better than the FFT method.

According to our investigations, the Gaussian wavelet has results similar to FFT results and therefore is useful for stratigraphy studies. From the results of our experiences, Morlet is suitable for structural (fault) and hydrocarbon potential studies, and finally, Mexican Hat has an average result compared to the two other wavelets mentioned. In this investigation, Morlet is a more applicable wavelet, and therefore all of our research has been carried out by using this wavelet. 

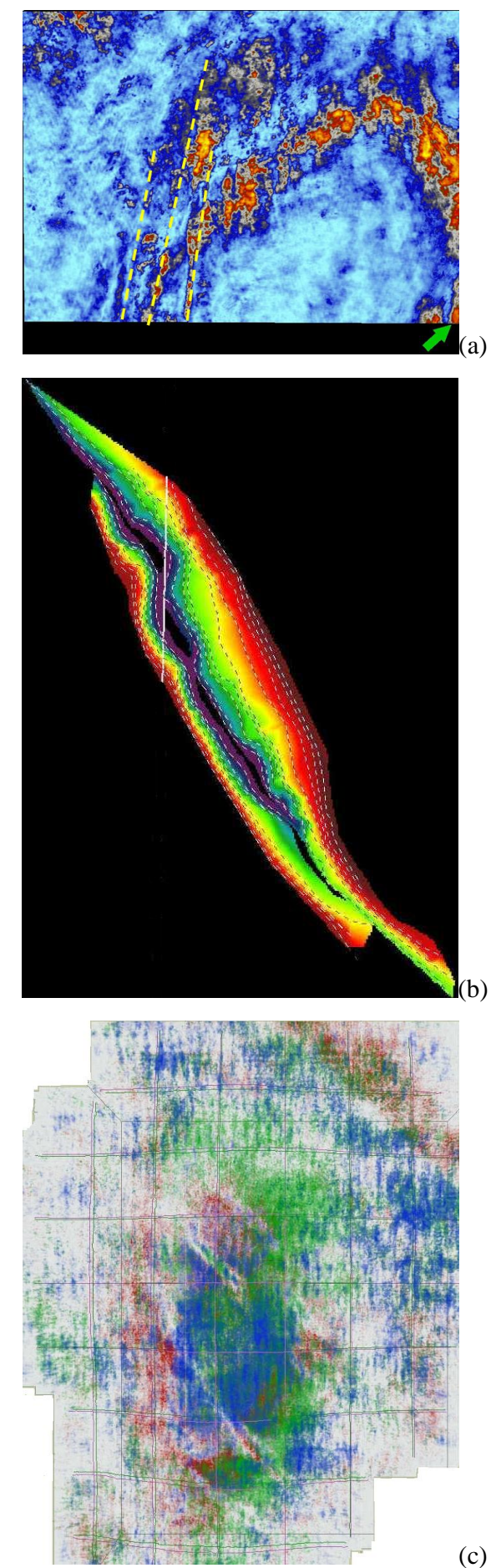

(c)

Fig. 5. (a): CWT result at a $10 \mathrm{~Hz}$ frequency timeslice. Yellow dashed lines display the abilities of the CWT method in fault system detection on data of the Persian Gulf, (b): a map that resulted from fault interpretation (graben) similar to our results in this investigation, and (c): combination displayed from three iso-frequencies by using the RGB multi-displaying technique as red, green and blue colors are equal with low $(10 \mathrm{~Hz})$, medium $(15 \mathrm{~Hz})$ and high frequency $(20 \mathrm{~Hz})$, respectively (Saadatinejad and Sarkarinejad, 2011).
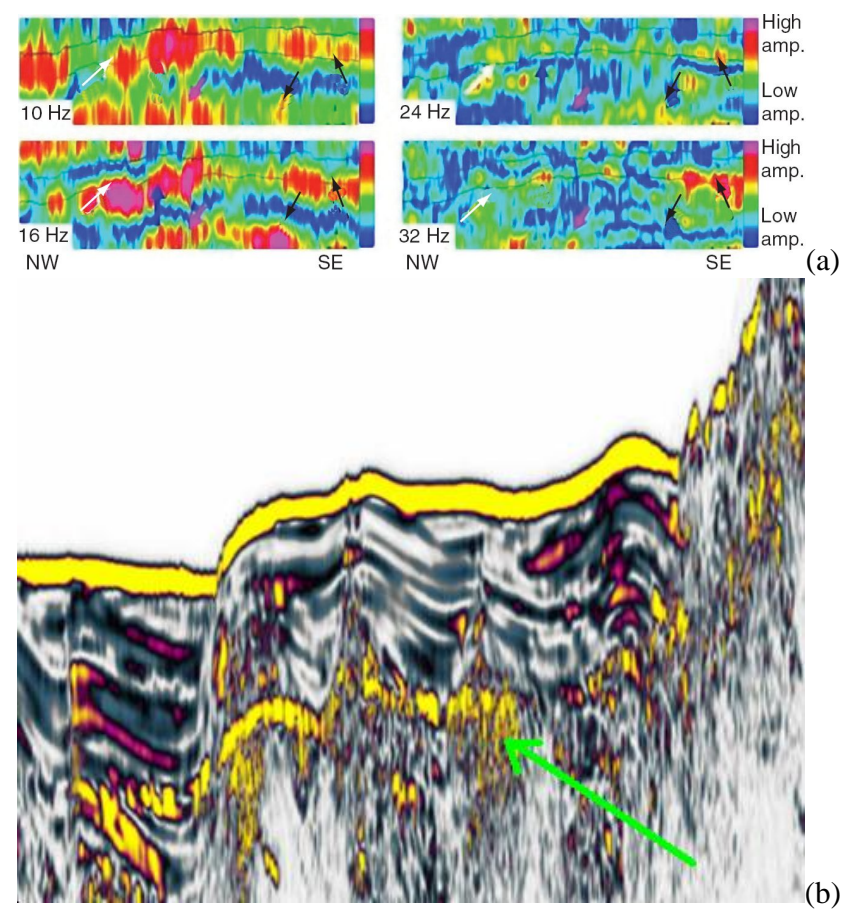

Fig. 6. The representation of results from spectral decomposition (CWT) in (a) the Sarvak formation in Iran (north of the Persian Gulf) (White, blue and black arrows represent spectral anomalies at the base of the reservoir formation (Saadatinejad and et. al., 2009) and (b) in another field in the Persian Gulf.

We can introduce the abilities of Morlet wavelets in two orders: velocity dispersion and energy attenuation of signals. Fault features disperse the signal that is reflected from it; this effect is known as velocity dispersion (Saadatinejad and Sarkarinejad, 2011). Therefore, wavelet transform can detect structural features (faults) better when the Morlet wavelet is used. In the case of energy attenuation in gas zones, crossing seismic signals through the reservoir causes energy absorption of gas, and Morlet wavelet effects in this situation are more than other wavelets. This phenomenon applies to detecting the area under reservoirs where attenuation of energy in high frequencies affected by gas creates low-frequency shadows.

\section{Discussion}

\subsection{Reservoir structures detection}

The CWT has more applications for detecting tectonic features, whereas FFT has more use for detecting stratigraphic features such as reefs. Figure 4 shows a comparison between the two main methods of spectral decomposition. Figure $4 \mathrm{a}$ displays spectral results of the FFT method and Fig. $4 \mathrm{~b}$ is the results of CWT on the same timeslice. In fact, this figure displays usage of the CWT technique in mapping some different 
structural geology events and showing some types of faults or ruptures. Red dashed lines indicate the number of extensional faults on CWT results in slice (b) better than FFT results in slice (a). Furthermore, this figure illustrates one of the most frequent applications of CWT in structure detection's special fault systems. By tracking and then mapping these ruptures in different timeslices, it is possible to identify various types of structural events and it can be a major key for geological interpretation, petroleum engineering studies, and reservoir development. Figure 5a displays CWT results on a timeslice from the Persian Gulf data at $10 \mathrm{~Hz}$ frequency, and by picking the CWT and fault interpretation, the results showed a graben map similar to our results in previous investigation in the Fig. 5b (Saadatinejad and Sarkarinejad, 2011).

Now and in an innovative experiment, we can animate three frequencies together by using the RGB technique as a quick and effective interpretation tool; this technique was tested successfully in previous studies (Saadatinejad et al., 2011). In this technique, we show three different frequencies with three basic colors (red, green, blue) to illustrate variations of suitable geological events, and we correspond these colors to low, mid- and high frequencies, respectively, and therefore they illustrate a trend from the thick to the thinner parts. Now this multicolor composite displaying (RGB) can simultaneously show the distribution of stratigraphic and structural features such as extensional systems (Fig. 5c). The main body of events are shown in red, the middle parts are visible in green, and the filling and thin parts of the body are obvious in blue.

\subsection{Hydrocarbon exploration}

Although different geoscientist groups have already studied many parts of the formations of the studied area, their findings did not have satisfying results. In fact, they could not attain any geological and seismic evidence to support that they succeeded in mapping the formation completely and discovered the object structure in others formations. Thus, our attempts concentrated on utilizing CWT as a useful and feasible spectral analysis method to get acceptable results from the investigation of the structural system and evaluation of its hydrocarbon in the mentioned formations, respectively.

To show the seismic responses in different frequencies, scientists usually animate and display some different isofrequency maps, and thus we used this technique for some Iranian oil fields in the Persian Gulf. In Fig. 6a we showed the application of CWT in four different sections to detect the exploration of hydrocarbon in a potential reservoir in a field north of the Persian Gulf. Frequency cubes were extracted at frequencies of 10, 16, 24 and $32 \mathrm{~Hz}$ on the Sarvak formation and picked the top and base of the reservoir member (Mishrif) to check low-frequency shadows.

Accordingly, different iso-frequencies from CWT anomalies are shown with black-, blue- and white-colored arrows at the boundary of the target member, while green and pink arrows are at the boundary between lower members. It is observed that the interface between the Mishrif (target member) and Ahmadi member acts completely differently than the surrounding limestone when viewed at discrete frequencies. This is even more apparent when all of the frequency maps are viewed as a movie. The CWT technique has distinctly different dynamic frequency responses than the background, probably because the hydrocarbons have changed the reflectivity of the reservoir. The anomalies at the left of this figure are bright at $10 \mathrm{~Hz}$, while the anomalies at the right of the figure exhibit no apparent anomalies compared with the left anomalies. A high-energy low-frequency shadow zone can be observed under the Mishrif member in the left of the figure. In the $14 \mathrm{~Hz}$ section, both left and right anomalies stand out, and the difference between them becomes relatively weak; yet, the left anomalies are still brighter than the right anomalies and the background. At a frequency of $24 \mathrm{~Hz}$, the left anomalies become completely invisible, and in the high-frequency $32 \mathrm{~Hz}$ section, the right anomalies are more explicit and brighter than the left anomalies. In the left anomalies, frequency shadows associated with anomalies are observable in the low-frequency range, while right anomalies stand out in the frequency ranges between $24-32 \mathrm{~Hz}$. The anomalies at the right of this figure indicate the presence of hydrocarbons in this reservoir in the reef structure (Saadatinejad et al., 2012).

Another field in the Persian Gulf has the same results. Figure $6 \mathrm{~b}$ shows the CWT method that was applied on the vertical seismic section in an iso-frequency map. It also shows that low-frequency shadows have higher amplitudes beneath the reservoir, and these highlighted anomalies are indicated by a green arrow.

Although adapting the CWT by using the Morlet wavelet in an area including velocity dispersion and energy attenuation is better than other spectral decomposition methods, especially FFT, its computing speed and flexibility in displaying reservoir stratigraphy in comparison with FFT is weak and powerless (Saadati Nejad et al., 2009).

\section{Conclusions}

Wavelet transform (especially continuous mode) is an effective method with extensive uses in the petroleum engineering industry. As a result of these wide applications, effective structural systems are visible in the horizontal section rather than in CWT vertical results, and some important oil reservoirs have been mapped in Iran. The CWT is able to detect fault systems and hydrocarbon in reservoirs better than the FFT method while in stratigraphy studies, the FFT has better results than the CWT.

On the other hand, CWT is used for showing the presence of hydrocarbon by using the so-called effect of lowfrequency shadows under gas reservoirs. One can clearly see that the hydrocarbons are responsible for the high amplitudes 
at and around $32 \mathrm{~Hz}$ and the associated dimming at $47 \mathrm{~Hz}$. They are also responsible for subtle changes in reflectivity at other frequencies.

The Morlet wavelet with special and useful characters, rather than other wavelets such as Gaussian and Mexican Hat, is suitable for this kind of study according to our investigational experiments. However, the CWT with the Morlet wavelet shows results with lower resolution than other wavelets and other spectral decomposition methods. The reason could be related to the presence of more sidelobes in the Morlet rather than the other wavelets.

Acknowledgements. The authors are grateful to the NIOC for their scientific and financial support, especially geophysics experts of the Exploration Directorate. The authors also are thankful for Mrs. Ranjbaran for her attempts to edit this article.

Edited by: V. Prasad Dimri

Reviewed by: R. Srivastava and one anonymous referee

\section{References}

Abdollahie Fard, I., Braathen, A., Mokhtari, M., and Alavi., A.: Interaction of the Zagros fold-thrust belt and Arabian-type, deepseated folds in the Abadan plain and the Dezful embayment, SW Iran, Petrol. Geosci., 12, 347-362, 2006.

Burnett, M. D. and Castagna, J. P.: Advances in spectral decomposition and reflectivity modeling in the Frio formation of the Gulf Coast, Search and Discovery, 40113, http://www.searchanddiscovery.com/documents/2004/burnett/ images/burnett.pdf, 2004.

Castagna, J. P., Sun, S., and Siegfried, R. W.: Instantaneous spectral analysis: Detection of low frequency shadows associated with hydrocarbons, The Leading Edge, 22, 120-7, 2003.
Castagna, J. P. and Sun, S.: Comparison of spectral decomposition methods, first break, 24, 75-79, March 2006.

Dimri, V. P., Vedanti, N., and Chattopadhyay, S.: Fractal analysis of aftershock sequence of Bhuj earthquake - a wavelet based approach, Curr. Sci., 88, 1617-1620, 2005.

Ghazban, F.: Petroleum Geology of the Persian Gulf, University of Tehran, ISBN: 964-03-9420-3, 2007.

Goloshubin, G. M., Korneev, V. A., and Vingalov, V. M.: Seismic low-frequency effects from oil saturated reservoir zones, SEG International Exposition and 72nd Annual Meeting, 2002.

Liner, C.: An overview of wavelet transform concepts and applications, University of Houston, 1-17, 26 February 2010.

Mallat, S.: A wavelet tour of signal processing, Academic Press, London, 178, 1999.

Saadati Nejad, M. R., Hasani, H., Mohammado Khorasani, M., Javaherian, A. and Sokooti, M. R.: Application of spectral decomposition seismic attribute for identification geological characteristics, 71st EAGE Conference \& Exhibition-Amsterdam, The Netherlands, 2009.

Saadatinejad, M. R. and Sarkarinejad, K.: Application of the spectral decomposition technique for characterizing reservoir extensional system in the Abadan Plain, southwestern Iran, Mar. Petrol. Geol., Elsevier, March, 1205-1217, 2011.

Saadatinejad, M. R., Hassani, H., and Javaherian, A.: Representation of the thickness distribution of channels and stratigraphic events at one of the Iranian filed in Hormuz Strait using composite plot and RGB display technique of spectral decomposition, J. Geophys. Eng., July, 8, 412-421, 2011.

Saadatinejad, M. R., Javaherian, A., and Sarkarinejad, K.: Investigation of the various spectral decomposition methods to detect and explore hidden complex reservoir structures and their hydrocarbon potentials in northwestern part of the Persian Gulf, Journal of Energy Exploration and Exploitation, July, 30, 867-887, 2012.

Sinha, S., Routh, P. S., Anno, P. D., and Castagna, J. P.: Spectral decomposition of seismic data with continuous-wavelet transform, Geophys., 70, 19-25, 2005. 